Pol. J. Food Nutr. Sci., 2020, Vol. 70, No. 4, pp. 409-418

On-line ISSN: 2083-6007

Print ISSN: $1230-0322$

DOI: $10.31883 /$ pjfns/130255 http://journal.pan.olsztyn.pl

Original research article

Food Quality and Functionality Section

\title{
Aronia melanocarpa Leaves as a Source of Chlorogenic Acids, Anthocyanins, and Sorbitol, and Their Anti-Inflammatory Activity
}

\author{
Agnieszka Zielińska $^{1 *} \odot$, Dorota Bryk ${ }^{2}$, Katarzyna Paradowska ${ }^{1}$, Iwona Wawer $^{3}($ \\ ${ }^{1}$ Department of Physical Chemistry, Chair of Physical Pharmacy and Bioanalysis, Faculty of Pharmacy, \\ Medical University of Warsaw, Banacha Str. 1, 02-097 Warsaw, Poland \\ ${ }^{2}$ Chair of Biochemistry and Clinical Chemistry, Faculty of Pharmacy, Medical University of Warsaw, \\ Banacha Str. 1, 02-097 Warsaw, Poland \\ ${ }^{3}$ Herbology Department, Carpathian State University, Rynek 1, 38-400 Krosno, Poland
}

Key words: Aronia melanocarpa leaves, sorbitol, chlorogenic acids, anti-inflammatory activity, NMR, HPLC

Aronia melanocarpa E. berries are a valuable component of the healthy diet. They are extremely high in phenolics exhibiting strong antioxidant properties. However, not much information is available on the chemical composition and bioactive potential of chokeberry leaves. Therefore, the analyses of sugars and phenolics of extracts from chokeberry leaves collected from June to October were performed using spectroscopic (NMR) and chromatographic (HPLC-DAD/RI, GC-MS) methods. The leaf extracts contained a significant amount of sorbitol, especially those made of leaves collected since June to July (avg. $145.2 \mathrm{mg} / \mathrm{g} \mathrm{d.w.).} \mathrm{The} \mathrm{average} \mathrm{contents} \mathrm{of} \mathrm{Cya-3-Gal} \mathrm{and} \mathrm{chlorogenic} \mathrm{acids} \mathrm{in} \mathrm{the} \mathrm{extracts} \mathrm{were} \mathrm{at} 0.52 \mathrm{mg} g$ d.w. and up to $13.1 \mathrm{mg} / \mathrm{g}$ d.w., respectively. Chokeberry leaf extracts from green and red leaves were subjected to the in vitro study on human umbilical vein endothelial cells (HUVECs). Both extracts suppressed TNF- $\alpha$-induced surface expression of ICAM-1 and VCAM-1 molecules, and exhibited anti-adhesive and anti-inflammatory properties. Green and red leaves may foster a therapeutic potential in the prevention of atherosclerosis and other pathological events involving leucocyte adhesion. That is why chokeberry leaves can be considered as a promising component of functional foods owing to the high content of chlorogenic acids and sorbitol.

\section{ABBREVIATIONS}

CGA - chlorogenic acid, 3-O-caffeoylquinic acid (CAS 327-97-9); nCGA - neochlorogenic acid, 5-O-caffeoylquinic acid (CAS 906-33-2); iCGA - isochlorogenic acid A, 3,5-dicaffeoylquinic acid (CAS 2450-53-5); Cya-3-Gal - cyanidin 3-O-galactoside (CAS 27661-36-5); TNF $\alpha$ - tumor necrosis factor alpha; ICAM-1 - intercellular adhesion molecule 1; VCAM-1 - vascular cell adhesion molecule 1; CAMs - cell adhesion molecules; HUVECs - human umbilical vein endothelial cells.

\section{INTRODUCTION}

Aronia melanocarpa [Michx.] Elliot [Hardin, 1973; Strigl et al., 1995] is a member of the Rosaceae family; commonly called the black chokeberry, chokeberry or simply aronia. It is cultivated in Poland and other European countries as well as in the USA and South Korea. Its fruits are most frequently used to produce juice, syrup, jam, jellies, wine, and herbal teas. Earlier studies were focused on the chemical composi-

\footnotetext{
* Corresponding Author:

E-mail: agnieszka.zielinska@wum.edu.pl (A. Zielińska)
}

tion and biological activity of the fruits. Recently, an increased interest in aronia has been observed because of the nutritional benefits of the berries and their role in the prevention of degenerative diseases. The berry extracts and juice showed antioxidant, antiatherosclerotic, antidiabetic, anti-inflammatory, antiviral, and antimutagenic properties [Chrubasik et al., 2010; Kokotkiewicz et al., 2010; Kulling \& Rawel, 2008].

There are only a few studies available on the composition and potential application of chokeberry leaves. As by-products of aronia cultivation, they are plentiful and cheap raw material. The leaves are green in the spring and summer, and turn red and become decorative in the autumn. Chokeberry leaves may exhibit interesting biological effects due to the content of phenolic compounds and their high antioxidant activity [Thi \& Hwang, 2014]. Among their phenolic components, flavonoids (glycosides of cyanidin, quercetin, isorhamnetin and apigenin, and kaempferol derivative), hydroxycimmanic acids (chlorogenic, neochlorogenic, and dicaffeoylquinic acids), and proanthocyanidins (oligomers and polymers) were detected using HPLC-MS/MS [Lee et al., 2014; Teleszko \& Wojdyło, 2015].

A. melanocarpa fruits have an interesting free sugar profile. They contain significantly more sorbitol than fructose, glucose, and sucrose [Denev et al., 2018; Yang et al., 2019]. Sugar alcohols (polyols): sorbitol, mannitol and xylitol, were 
found in several wild berries [Mäkinen \& Söderllng, 1980]. Sorbitol and mannitol occurred most abundantly in rowan berries (Sorbus aucuparia), with their contents reaching up to 5.3 and $0.38 \mathrm{mg} / \mathrm{g}$ of fresh weight, respectively. Polyols are used as sugar replacers [Livesey, 2003]. They are low glycemic, low insulinemic, low-energy, and osmotic (colon-hydrating, laxative). The glycemic index (GI) and insulinemic index (II) of sorbitol are 9 and 11, respectively (sucrose 65 and 43, respectively, and glucose 100 and 100, respectively). An average diet provides 2.6-5.8 g of polyols per day [Lee, 2015]. Dried prunes (9-18 g of sorbitol/100 g) are one of the highest sorbitol-containing Rosaceae fruit. However, to the best of our knowledge, sugar composition of chokeberry leaf has not yet been determined. The Food and Drug Administration (FDA) has asserted that sorbitol is generally recognized as safe (GRAS, 21CFR184.1835).

Chlorogenic acids (CGAs) are the main phenolic compounds of chokeberry [Thi \& Hwang, 2014]. They also occur in remarkable quantities in coffee beans, cocoa, apples, and berry fruits (blackberry, mulberry) [Clifford, 2000]. Chlorogenic acid exhibits high antioxidant activity [Marinova et al., 2009] due to the ability to scavenge free radicals and modulate antioxidant enzyme gene expression [Gugliucci \& Bastos, 2009]. CGAs reduce glucose absorption, act as a protective agent to liver cells, and may offer clinical benefits in the treatment of neurodegenerative diseases [Mikami \& Yamazawa, 2015].

Anthocyanins are plant pigments classified as natural non-nutritive substances, their presence being indicated by dark red color of fruits and leaves. Young leaves deficient in chlorophyll as well as old leaves are red in color. Discoloration of old leaves results from atmospheric factors, e.g., cold weather or ultraviolet radiation [Lee, 2002; Szopa et al., 2017; Thi \& Hwang, 2014; Zou et al., 2012]. The dominant pigments in aronia fruits are cyanidin 3-O-galactoside and cyanidin 3-O-arabinoside [Zielińska et al., 2020]. Anthocyanins provide a range of health benefits, they can reduce oxidative stress, act as anti-inflammatory agents, or regulate glucose concentration in the blood. It has been demonstrated that the intake of aronia juice and the extracts lowers blood pressure and reduces serum levels of total cholesterol, LDL cholesterol, and triglycerides in patients with the metabolic syndrome [Skoczyńska et al., 2007]. Moreover, berry extracts were found to reduce the levels of cardiovascular risk markers, such as oxidized low-density lipoprotein (oxy-LDL), C-reactive protein (CRP), interleukin 6 (IL-6), soluble intercellular adhesion molecule-1 (sICAM-1), serum-soluble vascular cell adhesion molecule-1 (sVCAM-1), or monocyte chemoattractant protein 1 (MCP-1) in patients after myocardial infarction [Naruszewicz et al., 2003, 2007]. Based on in vitro studies and animal experiments, it is assumed that most of the beneficial activity of A. melanocarpa extracts is due to the high anti-oxidative activity of polyphenols, especially anthocyanins [Chrubasik et al., 2010]. The studies on endothelial cells have provided new insights into understanding the molecular mechanisms underlying their beneficial effects, besides antioxidative and radical scavenging ones [Xia et al., 2009]. The in vitro studies have demonstrated that the A. melanocarpa fruit extract inhibits 7b-hydroxycholesterol-induced apoptosis of endothelial cells [Zapolska-Downar et al., 2012]. Human umbilical vein endothelial cells (HUVECs) were treated with various concentrations of the commercial chokeberry fruit extract prior to the treatment with a tumor necrosis factor alpha $(\mathrm{TNF} \alpha)$. The surface protein and mRNA expression of cell adhesion molecules ICAM-1 and VCAM-1, as well as the adhesion of peripheral blood mononuclear leucocytes (PBMLs) to HUVECs were evaluated [Chang et al., 2010]. The endothelial adhesiveness to PBMLs and the expression of adhesion molecules in endothelial cells can also be influenced by chlorogenic acid [Bagchi et al., 2002] or proanthocyanidins.

The aim of this study was to perform a qualitative and quantitative analysis of the phenolic compounds and sugars of leaf water extracts of chokeberry var. 'Nero', as well as to track their changes in the growing season (from flowering to fruit ripening) by means of chromatographic methods (high-performance liquid chromatography with UV/VIS diode array and refractive index detection, HPLC-DAD/RI; gas chromatography - mass spectrometry, GC-MS) and spectroscopic methods (nuclear magnetic resonance, NMR). A further goal was to investigate the anti-inflammatory activity of the extracts in the in vitro study on human umbilical vein endothelial cells (HUVECs). Water was chosen as the solvent because of the potential use of the leaves in herbal teas.

\section{MATERIALS AND METHODS}

\section{Plant material}

Aronia melanocarpa (Michx.) Elliott leaves were collected at an ecological plantation (Organic Nursery Aronia Eggert, Grójec, Poland), from June until October 2013. Plant material was authenticated by Mr. Piotr Eggert (M.Sc.). A voucher specimen (no 10192) was deposited at the herbarium of the Department of Biology and Pharmaceutical Botany, Medical University of Gdansk, Poland. The leaves were collected from the moment they were young but shaped until turning red, for a period of five months. Harvesting was performed on the following days : June 4 and 26, July 18 and 26, August 16, September 2 and 21, October 18, collecting about $250 \mathrm{~g}$ of leaves from three selected, healthy, and well-defined shrubs on the plantations (from the same shrubs at all collection periods). All leaf samples were frozen immediately after collection and lyophilized. The lyophilized leaves were ground into powder and stored at $-70^{\circ} \mathrm{C}$ until extraction and analyses.

\section{Chemicals}

All standards, reagents, and solvents were of analytical or gradient grade. HPLC standards: chlorogenic acid (CGA, CAS 327-97-9), neochlorogenic acid (nCGA, CAS 906-33-2), isochlorogenic acid A (iCGA, CAS 2450-53-5), and cyanidin 3-O-galactoside (Cya-3-Gal, CAS 27661-36-5) were purchased from PhytoLab GmbH \& Co. KG, (Vestenbergsgreuth, German), sold as a primary reference standard with certified absolute purity. D-Sorbitol (99\%, CAS 50-70-4), d$(+)$-glucose $(\geq 99.5 \%)$, D- $(-)$-fructose $(\geq 99 \%)$, and sucrose $(\geq 99.5 \%)$ were purchased from Sigma-Aldrich (St. Louis, MO, USA). Other chemicals were purchased from Sigma-Aldrich and Avantor Performance Materials S.A. (Gliwice, 
Poland). Ultra-pure water (Millipore Milli-Q) was used for sample preparation.

Human umbilical vein endothelial cells (HUVECs), EBM-2 (Endothelial basal medium), EGM-2 Bulletkit = EBM-2 + all growth supplements, fetal bovine serum (FBS), Hanks' balanced salt solution (HBSS), trypsin-EDTA (ethylenediaminetetraacetate), and trypsin neutralizing solution (TNS) were obtained from LONZA (Basel, Switzerland). 3-(4,5-Dimethylthiazol-2-yl)-2,5-diphenyltetrazolium bromide (MTT), dimethyl sulfoxide (DMSO), and non-enzymatic cell dissociation solution were provided by Sigma (St. Louis, MO, USA). Human recombinant $\mathrm{TNF} \alpha$, phycoerythrin (PE) - conjugated mouse monoclonal antibody anti-human ICAM-1, fluorescein isothiocyanate (FITC) - conjugated mouse anti-human VCAM-1 monoclonal antibody, and suitable conjugated mouse IgG isotypes were all purchased from Becton Dickinson (San Diego, CA, USA). All other chemicals were purchased from Sigma-Aldrich.

\section{Extraction}

The leaf samples of 0.5 gram were weighed out. Then, $50 \mathrm{~mL}$ of boiling deionized water was added and the samples were kept at $90^{\circ} \mathrm{C}$ for $30 \mathrm{~min}$. Next, they were passed through a sintered glass filter under reduced pressure and evaporated to dryness using a Heidolph Hei-VAP Core rotary evaporator (Heidolph Instruments, Schwabach, Germany). Three extracts were prepared for each batch. Next, the dry samples were dissolved in $10 \mathrm{~mL}$ of $80 \%(v / v) \mathrm{MeOH}$ (to remove polymerized sugars), filtered through a sintered glass filter, and evaporated to dryness using a rotary evaporator. To obtain carbohydrate fractions, the extracts were dissolved in $80 \%(v / v) \mathrm{MeOH}$, loaded on an RP-18 column $(10 \times 100 \mathrm{~mm})$, and eluted under increased pressure of 80 bar (Waters HPLC pump 515, Waters Corp., Milford, MA, USA), with $50 \mathrm{~mL}$ of $80 \%(\mathrm{v} / \mathrm{v}) \mathrm{MeOH}$ (first fraction, SF), later with $100 \%$ methanol (second fraction), eventually with chloroform to clean the column. The SF contained water-soluble carbohydrates and chlorogenic acids, the second fraction contained other phenolics. The fractions were evaporated to dryness and stored in a freezer for further analysis.

\section{Sugar and sorbitol content analysis by HPLC-RI and GC-MS}

The HPLC-RI quantitative analysis was carried out using a Hitachi Chromaster HPLC system with an RI detector and a Purospher STAR $\mathrm{NH}_{2}(5 \mu \mathrm{m}, 4 \times 250 \mathrm{~mm})$ column, under isocratic conditions, mobile phase: acetonitrile/water 75:25 ( $\mathrm{v} / \mathrm{v})$, a flow rate: $1 \mathrm{~mL} / \mathrm{min}$. The concentration of sorbitol was determined using a calibration curve generated for sorbitol, glucose, fructose, and sucrose standards. The linearity of the method was assessed based on the value of the coefficient of determination $\left(\mathrm{R}^{2}\right)$ of the calibration curve obtained for each standard (Table 1). The limit of detection (LOD) and limit of quantification (LOQ) concentrations were set using equations: $\mathrm{LOD}=3.3 \times \sigma / \mathrm{S}$ and $\mathrm{LOQ}=10 \times \sigma / \mathrm{S}$, where $\sigma$ is the standard deviation of the $y$-intercept and $S$ is the slope of the calibration curve (Table 1 ). The results of method accuracy analysis showed low values of $\% \operatorname{RSD}(<2)$ for interday variation. The recovery results were within the acceptable limit (recovery ranged from 97 to 103\%) of the interday variation, which indicated that the method is accurate. There was no significant change observed for the chromatograms of the standard solution and the experimental solution.

For the GC measurement, trimethylsilyl derivatives of the extract compounds and sugar standards were obtained with the BSTFA ( $N, O$-bis (trimethylsilyl) trifluoroacetamide) and TMCS (trimethylchlorosilane) mixture, according to Bstfa+Tmcs Spec. [1997]. The composition of derivatized samples was determined using the GC system coupled to an Agilent 7890A \& 5975C MS detector (Santa Clara, CA, USA). The column and analytical parameters were as follows: HP$5 \mathrm{MS}$ capillary column $(30 \mathrm{~m} \times 0.25 \mathrm{~mm} \times 0.25 \mu \mathrm{m}$, Agilent $)$, carrier gas - helium $(1 \mathrm{~mL} / \mathrm{min})$, temperature program $150^{\circ} \mathrm{C}$ for $3 \mathrm{~min}, 150-300^{\circ} \mathrm{C}, 5^{\circ} \mathrm{C} / \mathrm{min}$. The compounds were identified using reference mass spectra from the NIST Standard Reference Database. All the HPLC and GC retention times were confirmed using respective standards.

\section{Sorbitol analysis by NMR spectroscopy}

${ }^{13} \mathrm{C}$ NMR spectra were recorded at room temperature on a Varian VNMRS $300 \mathrm{MHz}$ spectrometer (Palo Alto, CA, USA) operating at $75 \mathrm{MHz}$ for ${ }^{13} \mathrm{C}$. The dry extracts were dissolved in DMSO- $\mathrm{d}_{6}$. Chemical shifts $(\delta)$ are given in ppm with TMS as an internal standard. NMR peak assignment for sorbitol is in agreement with the reported data [Ulrich et al., 2008].

\section{CGA and anthocyanin content analysis by HPLC-DAD}

Qualitative and quantitative analyses of the leaf extracts were performed using HPLC-DAD. Profiles of chlorogenic acids and anthocyanins were characterized simultaneously using the Hitachi Chromaster system (Tokyo, Japan) with a Purospher STAR RP-18e column (5 $\mu \mathrm{m}, 4 \times 250 \mathrm{~mm}$ ),

TABLE 1. Calibration curves, concentration range, limit of detection (LOD), and limit of quantification (LOQ) determined for sugar and sugar alcohol using the HPLC-IR method.

\begin{tabular}{|c|c|c|c|c|c|}
\hline Compound & Calibration curve ${ }^{\mathrm{a}}$ & $\mathrm{R}^{2}$ & $\begin{array}{c}\text { Linear range } \\
(\mathrm{mg} / \mathrm{mL})\end{array}$ & LOD (mg/mL) & LOQ $(\mathrm{mg} / \mathrm{mL})$ \\
\hline Sorbitol & $A=114479 c-709$ & 0.999 & $20.0-50.0$ & 0.51 & 1.55 \\
\hline Fructose & $A=437966 c-923$ & 0.997 & $0.25-2.5$ & 0.06 & 0.18 \\
\hline Glucose & $A=404226 c+711$ & 0.998 & $0.25-2.5$ & 0.05 & 0.15 \\
\hline Sucrose & $\mathrm{A}=448100 \mathrm{c}+962$ & 0.998 & $0.25-2.5$ & 0.05 & 0.15 \\
\hline
\end{tabular}

${ }^{\mathrm{a}} \mathrm{A}$ - peak area, c - concentration $(\mathrm{mg} / \mathrm{mL})$ of the compound. 
according to the methods validated and described in our publication on the chokeberry research [Zielińska et al., 2020]. A mobile phase gradient system consisting of $4.5 \%$ $(v / v)$ formic acid (A) and acetonitrile (B) was employed for the analysis. The gradient conditions were as follows: 0-5 $\min , 5 \% \mathrm{~B} ; 5-15 \mathrm{~min}, 5-8 \% \mathrm{~B} ; 15-50 \mathrm{~min}, 8-25 \% \mathrm{~B}$; 50-55 $\mathrm{min}, 25-50 \% \mathrm{~B} ; 55-65 \mathrm{~min}, 5 \% \mathrm{~B}$, flow rate: 1-15 min, $1 \mathrm{~mL} / \mathrm{min}$; $15-50 \mathrm{~min}, 0.8 \mathrm{~mL} / \mathrm{min}$; 50-65 min $1 \mathrm{~mL} / \mathrm{min}$. The anthocyanin chromatograms were monitored at $520 \mathrm{~nm}$, CGAs at $330 \mathrm{~nm}$, retention times were: nCGA $10.9 \mathrm{~min}$, CGA $20.5 \mathrm{~min}$, iCGA $22.3 \mathrm{~min}$, and CyaGal $26.8 \mathrm{~min}$. The concentrations of the compounds were determined using an appropriate calibration curve. All measurements were performed in triplicate.

\section{Anti-inflammatory activity of green and red chokeberry leaves in human endothelial cells}

\section{Materials}

Two extracts were selected for detailed testing of the antiinflammatory activity: from green leaves (collected on August 16) and red leaves (collected on October 18). The aim of the anti-inflammatory activity tests was to compare the properties of green and red leaves. Therefore, the samples with a similar CGA acid content were selected, one of which additionally contained anthocyanins. The August 16 leaves were healthy with no signs of reddening or wilting. In the case of a sample collected in the autumn, fully red leaves were selected (only sample form October 18 met this criterion).

The extracts were dissolved before use in the phosphate-buffered saline (PBS) solution containing 10\% DMSO $(10 \mathrm{mg} / \mathrm{mL})$ and further diluted with culture medium. All reagents were maintained at $-20^{\circ} \mathrm{C}$ and further dilutions were made with culture medium prior to use.

\section{Cell culture and experimental conditions}

Human umbilical vein endothelial cells were cultured in endothelial cell growth medium with $2 \%$ FBS. The cells were maintained at $37^{\circ} \mathrm{C}$ in $5 \% \mathrm{CO}_{2}$ in humidified atmosphere and used for experiments between passages 3 and 4 (doubling population $\leq 10$ ). For experiments, human umbilical vein endothelial cells were cultured in 6- or 12-well plates. When the HUVECs reached confluence, the cells were pretreated with the $A$. melanocarpa extract $(50 \mu \mathrm{g} / \mathrm{mL})$ for $2 \mathrm{~h}$. The cells were then treated with $\mathrm{TNF} \alpha(10 \mathrm{ng} / \mathrm{mL})$ for the indicated period of time. Cell viability remained constant in all experiments (above 90\%).

\section{Cell viability assessment by MTT assay}

Cell viability was assessed by determining the MTT salt conversion using mitochondrial dehydrogenase. Briefly, the cells were incubated for $24 \mathrm{~h}$ in 24 -well plates at a concentration of $50 \mu \mathrm{g} / \mathrm{mL}$ of the tested extracts, and then for another $4 \mathrm{~h}$ with $0.5 \mathrm{mg} / \mathrm{mL}$ of the MTT solution, which is converted in living cells to insoluble formazan under the influence of mitochondrial dehydrogenase. The converted pigments were then dissolved in $0.04 \mathrm{M} \mathrm{HCl}$ in absolute isopropanol. The absorbance of dissolved formazan was measured spectrophotometrically at $570 \mathrm{~nm}$ using an Epoch microplate reader
(BioTek Instruments Inc., Winooski, VT, USA) equipped with Gen5 software. Cell viability remained constant in all experiments (above 90\%).

Measurement of ICAM-1 and VCAM-1 expression in human umbilical vein endothelial cells using flow cytometry

Resting HUVECs in 12-well plates were pretreated with the indicated concentration $(50 \mu \mathrm{g} / \mathrm{mL})$ of $A$. melanocarpa extracts for $2 \mathrm{~h}$ and then treated with $\mathrm{TNF} \alpha(10 \mathrm{ng} / \mathrm{mL})$ for $16 \mathrm{~h}$. After the experiments, the cells were washed with a phosphate-buffered saline solution (PBS). Next, they were harvested and washed in PBS containing 1\% FBS and resuspended in $100 \mu \mathrm{L}$ of the labeling buffer. Immediately after that, the cells were incubated with PE-conjugated mouse anti-human ICAM-1 and FITC-conjugated mouse anti-human VCAM-1 antibodies, in a dark place for $1 \mathrm{~h}$. For the isotype control, the cells were treated with PE-conjugated mouse anti-IgG1 antibody. The samples were washed again with PBS and analyzed (10,000 cells per sample) by flow cytometry using the FACSCalibur system (BD, Biosciences, San Jose, CA, USA) with the CellQuest Software. After correcting for non-specific binding using the isotype control, the mean fluorescence intensity was measured as an indicator of ICAM-1 and VCAM-1 surface protein expression.

\section{Statistical analysis}

The results were expressed as mean \pm standard deviation $(n=3)$. Statistica 10 (StatSoft Inc., Tulsa, OK, USA) was used for the statistical analysis of experimental results. One-way analysis of variance (ANOVA) was applied with Tukey test at a significance level of $\mathrm{p} \leq 0.05$.

\section{RESULTS AND DISCUSSION}

\section{Contents of sorbitol and sugars}

Simple carbohydrates can be distinguished by thin-layer chromatography (TLC), gas chromatography (GC), and high-performance liquid chromatography (HPLC). These methods have specific advantages and drawbacks. For GC separations, sugars have to be derivatized. In the case of the HPLC method, the detection of simple carbohydrates from highly colored small fruit samples may be disturbed by anthocyanins. Therefore, we used NMR spectroscopy which does not require chemical preparation of the sample and yields information on all sugars in one experiment (NMR spectrum).

The GC-MS analysis, performed prior to ${ }^{13} \mathrm{C} \mathrm{NMR}$, indicated that the major sugar of chokeberry leaves may be one of the sugar alcohols: sorbitol or mannitol (Table 2). Among other trimethylsilyl (TMS) derivatives, two peaks of glucose ( $\alpha$ - and $\beta$-glucopyranoside) and one of sucrose were identified, also quinic and caffeic acids - constituents of chlorogenic acid. However, the fructose peaks were not detected, probably due to the decomposition of fructose silyl derivatives.

The NMR analysis was performed to identify sugars in the leaf extracts. The ${ }^{13} \mathrm{C}$ NMR spectra of the sugar fraction of water extracts from aronia leaves showed six high resonances revealing the presence of sorbitol as the main 
TABLE 2. GC-MS data for trimethylsilyl (TMS) derivatives of the sugar fraction (SF) of chokeberry leaf extract (sample collected on October 18).

\begin{tabular}{|c|c|c|c|c|}
\hline Peak No & $\mathrm{t}_{\mathrm{R}}(\min )$ & Masses & $\begin{array}{c}\text { Relative content in SF } \\
\text { (\% of total area) }\end{array}$ & Compound \\
\hline 1 & 22.181 & 345,255 & 21.2 & Quinic acid (5 TMS) \\
\hline 2 & 22.490 & 204,191 & 6.4 & D-Glucose (5 TMS) \\
\hline 3 & 22.987 & $319,205,103$ & 44.9 & Sorbitol/mannitol (6 TMS) \\
\hline 4 & 23.356 & 204,191 & 10.2 & D-Glucose (5 TMS) \\
\hline 5 & 24.615 & 396,219 & 2.5 & Caffeic acid (3 TMS) \\
\hline 6 & 28.232 & 217,204 & 5.5 & Derivatization by-product \\
\hline 7 & 28.266 & 217,204 & 3.7 & Derivatization by-product \\
\hline 8 & 29.055 & $437,361,217$ & 5.5 & Sucrose (8 TMS) \\
\hline
\end{tabular}

Note: mass 73 and 147 for TMS groups are omitted in the table.

component. An exemplary spectrum of the sugar fraction (sample from July 24) is shown in Figure la. For comparison, ${ }^{13} \mathrm{C}$ NMR spectra (in DMSO-d6) of pure sorbitol and mannitol are illustrated in Figures $1 \mathrm{~b}$ and 1c, respectively. Chemical shifts are collected in Table 3. The spectra and data collected show that the sugar fraction of leaf extracts did not contain mannitol.

The ${ }^{13} \mathrm{C}$ NMR spectrum of the sugar fraction of water extract reveals two areas typical of saccharides (Figure 1a, Table 4). One of them is situated between $\delta 60$ and $80 \mathrm{ppm}\left(\mathrm{CH}\right.$ and $\mathrm{CH}_{2}$ carbons) and the other between $\delta 80$ and $106 \mathrm{ppm}$ where the signals of anomeric carbons of glucose ( $\alpha$ - and $\beta$-glucopyranose) and fructose ( $\alpha$ - and $\beta$-fructofuranoside) can be observed.

The HPLC analysis with a refractive index detector (HPLC-RI) and $\mathrm{NH}_{2}$ column was performed to determine the content of carbohydrates. Its results indicated that the minor soluble carbohydrates present in the water extract of chokeberry leaves at the levels of $1-4 \%$ were fructose, glucose, and sucrose $(3.3 \pm 0.1,2.2 \pm 0.1,6.1 \pm 0.3 \mathrm{mg} / \mathrm{g}$ of lyophilized leaves, respectively). The main sugar component, sorbitol, represented $\mathrm{ca}$. $80 \%$ of total carbohydrates, with the average content at $145.2 \pm 1.8 \mathrm{mg} / \mathrm{g}$ of lyophilized leaves. Its high content has also been determined in the leaves of other shrubs and fruit trees, e.g. at $60-80 \mathrm{mg} / \mathrm{g} \mathrm{d.w}$. on average in apples (depending on irrigation) [Naschitz et al., 2010], and at $30-40 \mathrm{mg} / \mathrm{g} \mathrm{d.w.} \mathrm{in} \mathrm{peaches} \mathrm{[Liu} \mathrm{et} \mathrm{al.,} \mathrm{2013].}$ On the other hand, its content in blueberries is as low as 0.02-0.05 mg/g d.w. [Fotiric Aksic et al., 2019]. Thus, the sorbitol content can vary widely in plants.

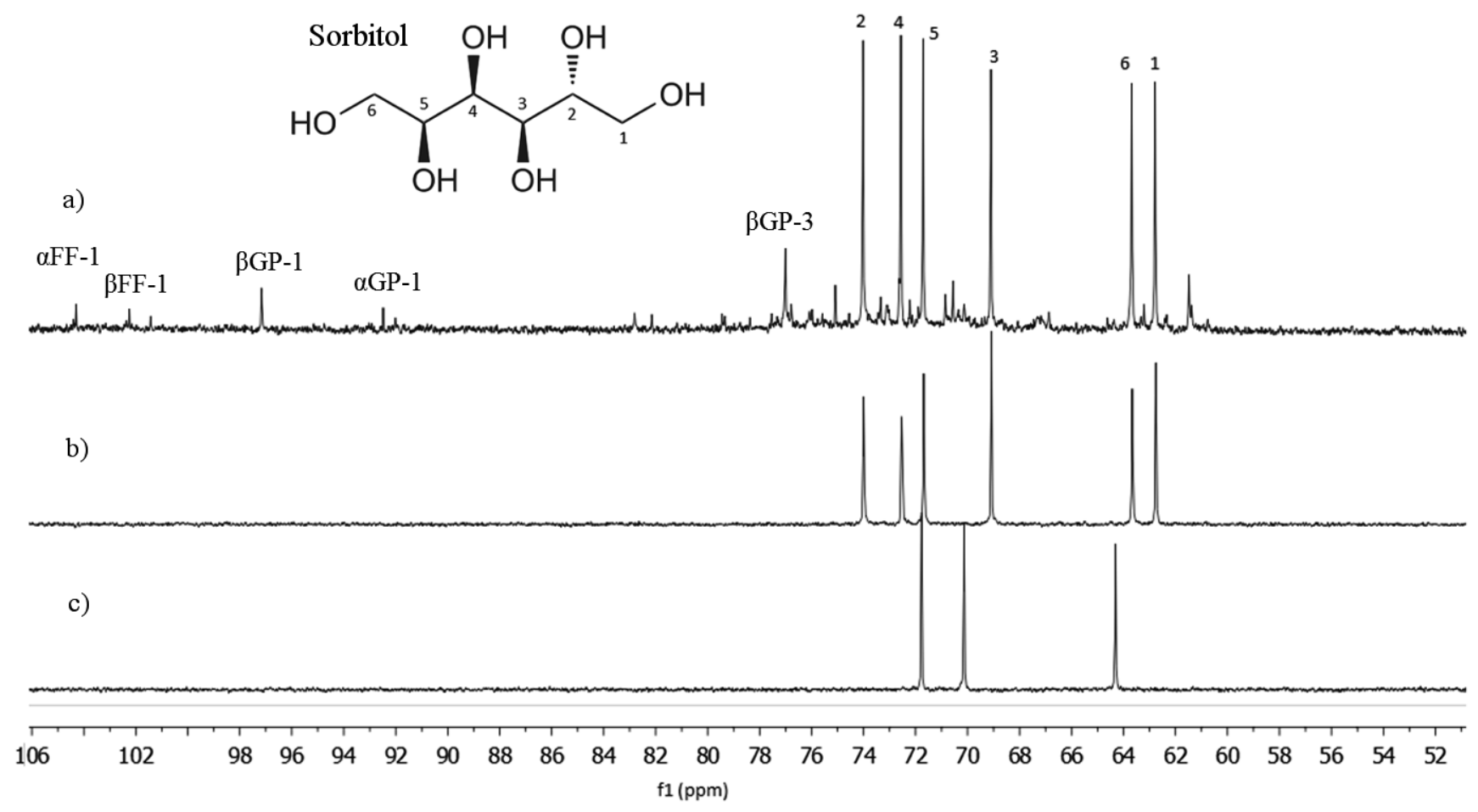

FIGURE $1 .{ }^{13} \mathrm{C}$ NMR spectra of a) the sugar fraction of the chokeberry leaf extract (sample from July 24) with the carbon numbering of sorbitol, b) sorbitol standard, and c) mannitol standard. GP - glucopyranose, FF - fructofuranoside. 
TABLE $3 .{ }^{13} \mathrm{C}$ NMR chemical shifts $(\delta, \mathrm{ppm})$ of sorbitol of the sugar fraction (SF) of chokeberry leaf extract (sample collected on July 26), and standards: sorbitol and mannitol.

\begin{tabular}{lcccc}
\hline Carbon & $\delta$ Sorbitol (SF) & $\delta$ Sorbitol std & $\delta$ Mannitol std \\
\hline 1 & 62.98 & 62.52 & 64.31 \\
2 & 74.22 & 73.77 & 71.77 \\
3 & 69.30 & 68.85 & 70.14 \\
4 & 72.92 & 72.30 & 70.14 \\
5 & 71.91 & 71.45 & 71.77 \\
6 & 63.88 & 63.43 & 64.31 \\
\hline
\end{tabular}

The changes of sorbitol content in A. melanocarpa leaves were observed during seasonal growth (Figure 2). In the spring, the content of sorbitol was high, later it decreased and remained unchanged during the summer. An increase was observed after fruit collecting (September 20) and the content decreased slightly at the end of the season (October 18). The pattern of changes can be related to flowering, fruit ripening, and removal. In Poland, the harvest usually takes place between the last week of August and the first week of September. The highest content of anthocyanins, vitamin $\mathrm{C}$, and reducing sugars in fruits was determined between August 29 and September 1, as reported by Andrzejewska et al. [2015] and Yang et al. [2019].

The fruit removal has a significant effect on the metabolism of the whole plant, including the leaves. The study on peach leaves [Nii, 1997] showed that the level of reducing and non-reducing sugars increased immediately after the harvest and then decreased successively, whereas the content of sorbitol also increased after fruit removal but remained high.

\section{CGAs and anthocyanins in chokeberry leaves during seasonal growth}

The HPLC studies have shown that Cya-3-Gal is responsible for the red color of the leaves. Other pigments pres-
TABLE $4 .{ }^{13} \mathrm{C}$ NMR chemical shifts $(\delta, \mathrm{ppm})$ of anomeric carbons $\mathrm{C} 1$ ( $\alpha$ - and $\beta$-glucopyranose and fructofuranoside of the sugar fraction of chokeberry leaf extract; sample collected on July 26).

\begin{tabular}{lc}
\hline Glucose/fructose & $\delta \mathrm{C} 1$ \\
\hline$\alpha$-Glucopyranose $(\alpha \mathrm{GP}-1)$ & 92.68 \\
$\beta$-Glucopyranose $(\beta \mathrm{GP}-1)$ & 97.35 \\
$\beta$-Glucopyranose $(\beta \mathrm{GP}-3)$ & 77.20 \\
$\alpha$-Fructofuranoside $(\alpha \mathrm{FF}-1)$ & 104.49 \\
$\beta$-Fructofuranoside $(\beta \mathrm{FF}-1)$ & 102.44 \\
\hline
\end{tabular}

ent in chokeberry fruits, mainly cyanidin-3-O-arabinoside [Zielińska et al., 2020], were below detection level in our study. The average content of anthocyanin Cya-3-Gal was found to be $0.52 \pm 0.01 \mathrm{mg} / \mathrm{g}$ dry weight (d.w.) of red leaves, which was relatively low compared to the fruit (2-3 g/100 g d.w.) [Gralec et al., 2019]. This content is lower than in the study by Szopa et al. [2017], were it reached $1.9 \mathrm{mg} / 100 \mathrm{~g}$ d.w.. These differences may result from various weather conditions in a given year (temperature during development, amount of sunshine and rainfall, time of leaf coloring).

The content of chlorogenic acids (nCGA, CGA, and iCGA) was determined in chokeberry leaf extracts collected from June till October (Figure 3). The average total content of CGAs was $13.1 \mathrm{mg} / \mathrm{g} \mathrm{d} . \mathrm{w}$. and $1.9 \mathrm{mg} / 100 \mathrm{mg}$ of the extract (range 1.46-2.59 mg/100 mg extract). The iCGA was present in the smallest amount. The content of all CGAs varied with the growth stages of the leaves. The highest CGAs content was observed in the extract of leaves collected in the initial growth phase, for instance in June before fruit ripening. At a further stage of growth, a decrease in the content of chlorogenic acids could be observed, with a slight increase in September. The decrease in CGAs content can be correlated with the appearance of anthocyanins in fruit, which takes place in the middle of July. A similar tendency was observed dur-

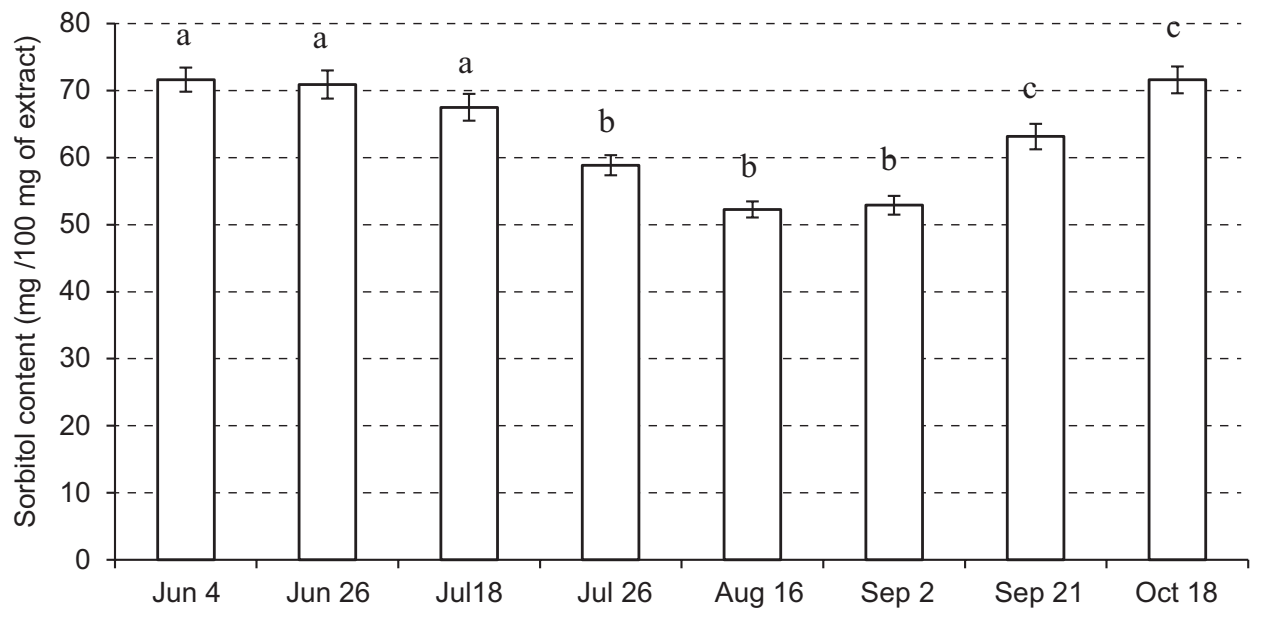

FIGURE 2. The sorbitol content in extracts from chokeberry leaves collected from June to October, Data are expressed as mean ( $\mathrm{n}=3$ ). Error bars indicate standard deviation. Different letters above bars indicate significant differences $(\mathrm{p} \leq 0.05)$. 


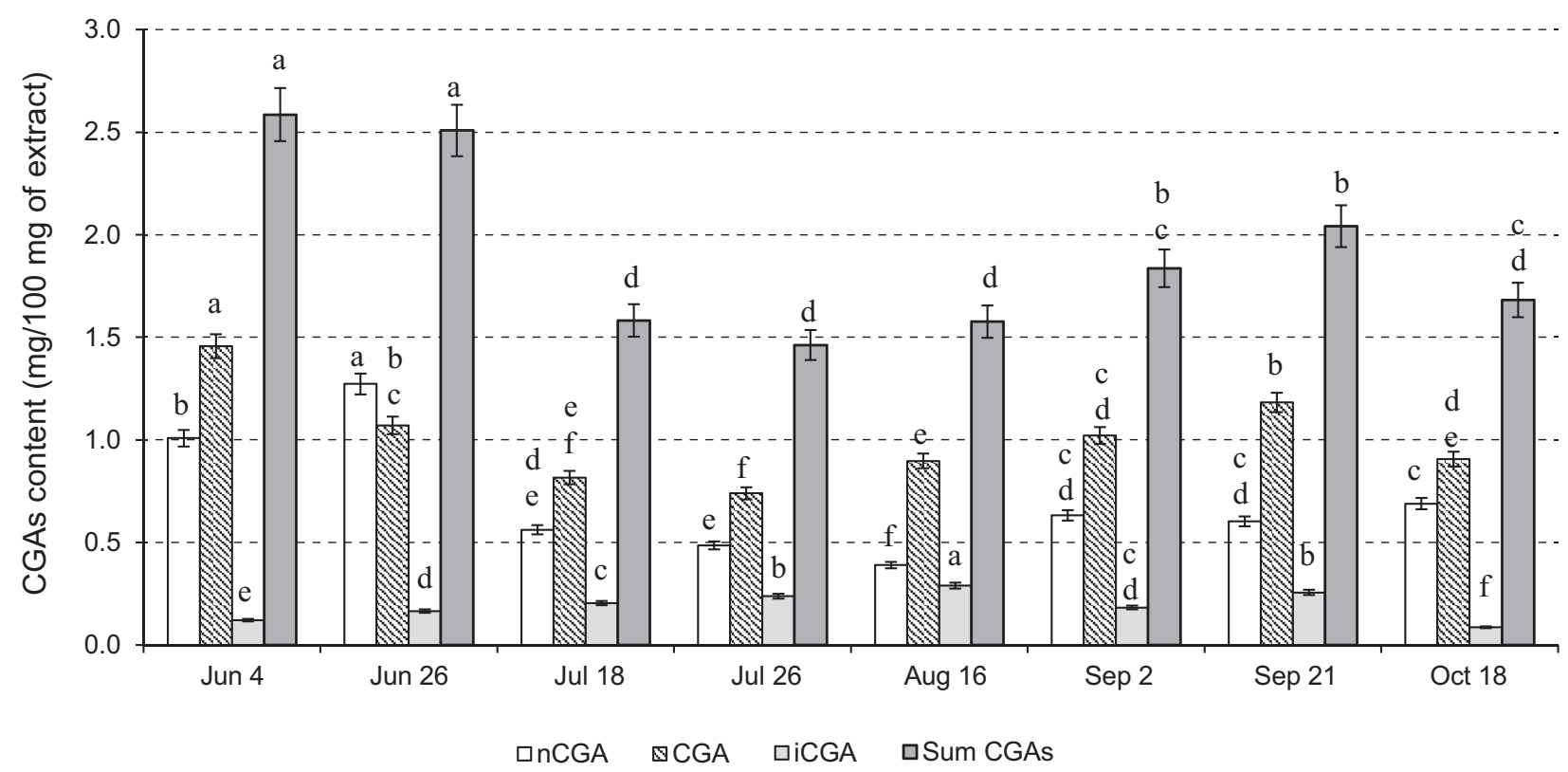

FIGURE 3. The chlorogenic acids (CGAs) content in water extracts of chokeberry leaves collected from June to October. Data are expressed as mean $(n=3)$. Error bars indicate standard deviation. Different letters above bars corresponding to the same compound indicate significant differences $(\mathrm{p} \leq 0.05)$. CGA - chlorogenic acid, nCGA - neochlorogenic acid, iCGA - isochlorogenic acid A.

ing the analysis of chokeberry fruit extracts during ripening [Zielińska et al., 2020]. In green fruit, the content of CGAs was remarkably high, then it decreased and remained unchanged till the end of the season (October). However, the content of both isomers (CGA and nCGA) was fivefold higher (avg. $70 \mathrm{mg} / \mathrm{g}$ d.w.).

Our research confirms previous reports that the chlorogenic acids are the main phenolic compounds present in A. melanocarpa leaves. Korean researchers [Thi \& Hwang, 2014] determined the content of CGAs in chokeberry leaves harvested at different stages of growth and extracted with two different solvents: distilled water and $80 \%$ ethanol, which turned out to have a significant impact on the CGAs content in the extract. The content of chlorogenic acid in distilled water and $80 \%$ ethanol extracts of chokeberry leaves was $17.2 \mathrm{mg} / \mathrm{g}$ and $22.8 \mathrm{mg} / \mathrm{g}$, respectively. These findings correspond quite well with the results obtained in the present study. In turn, the research by Szopa et al. [2017] showed that the dominant compounds in all analyzed leaf extracts from Aronia species (A. melanocarpa, A. arbutifolia, and A. $\times$ prunifolia) were chlorogenic and neochlorogenic acids. Their contents ranged from 184.0 to $678.2 \mathrm{mg} / 100 \mathrm{~g} \mathrm{d.w}$. and from 143.5 to $482.7 \mathrm{mg} / 100 \mathrm{~g}$ d.w., respectively.

\section{Anti-inflammatory activity of green and red chokeberry leaves in human endothelial cells}

Adhesion molecules are strongly involved in the formation of atherosclerotic plaques by mediating leukocyte migration. Here, we observed that both chokeberry leaf extracts (green leaves collected on August 16 and red leaves collected on October 18) reduced TNF- $\alpha$ induced surface expression of ICAM-1 and VCAM-1 molecules. The extract from the green leaves from the August harvest caused 1.2-fold inhibition of ICAM-1, which is stimulated by TNF $\alpha$. As for the surface expression of the TNF $\alpha$-stimulated VCAM-1 molecule, it was 1.3-fold inhibited by the extracts from the green leaves (Figure 4). The red leaf extract inhibited ICAM-1, which is stimulated by $\mathrm{TNF} \alpha$ (1.2-fold inhibition). As for the surface expression of the $\mathrm{TNF} \alpha$-stimulated VCAM-1 molecule, it was 1.3-fold inhibited by the extract from the red leaves The treatment of endothelial cells with leaf extracts alone had no effect on constitutively expressed levels of ICAM-1 or VCAM-1.

The red leaf extracts had a rather strong anti-inflammatory effect on endothelial cells. This is probably due to the presence of chlorogenic acids and anthocyanins. It should be noted that the content of Cya-3-Gal in the extracts was low $(0.18 \mathrm{mg} / 100 \mathrm{~g})$, whereas that of chlorogenic acids was ten times higher $(1.9 \mathrm{mg} / 100 \mathrm{~g})$. Surprisingly, the anti-inflammatory effect was similar to that of the green leaf extract which has no anthocyanins but contains chlorogenic acids as the main phenolic ingredient. Thus, the CGAs may be the key compounds determining these properties. These two extracts also contained sorbitol, but its role was not assessed. In conclusion, both leaf extracts are valuable and can be used in the future to prepare medicinal products against inflammation and degenerative diseases, such as cardiovascular diseases.

It seemed interesting to consider the results of the study on chokeberry leaves from South Korea [Lee et al., 2014]. The antioxidant capacities of the leaf extracts were determined as the $\mathrm{DPPH}^{\bullet}$ and $\mathrm{ABTS}^{\cdot+}$ scavenging activities, which were the highest for young leaves, followed by the mature and aged ones. This antioxidant activity trend may be associated with the total phenolic content, particularly with that of the chlorogenic acid derivatives. Younger chokeberry leaves may be utile for processing into high-quality functional tea, as they had the highest phenolic content. Our results on the content of chlorogenic acids and anti-inflammatory activity support this assumption. However, there is no significant 

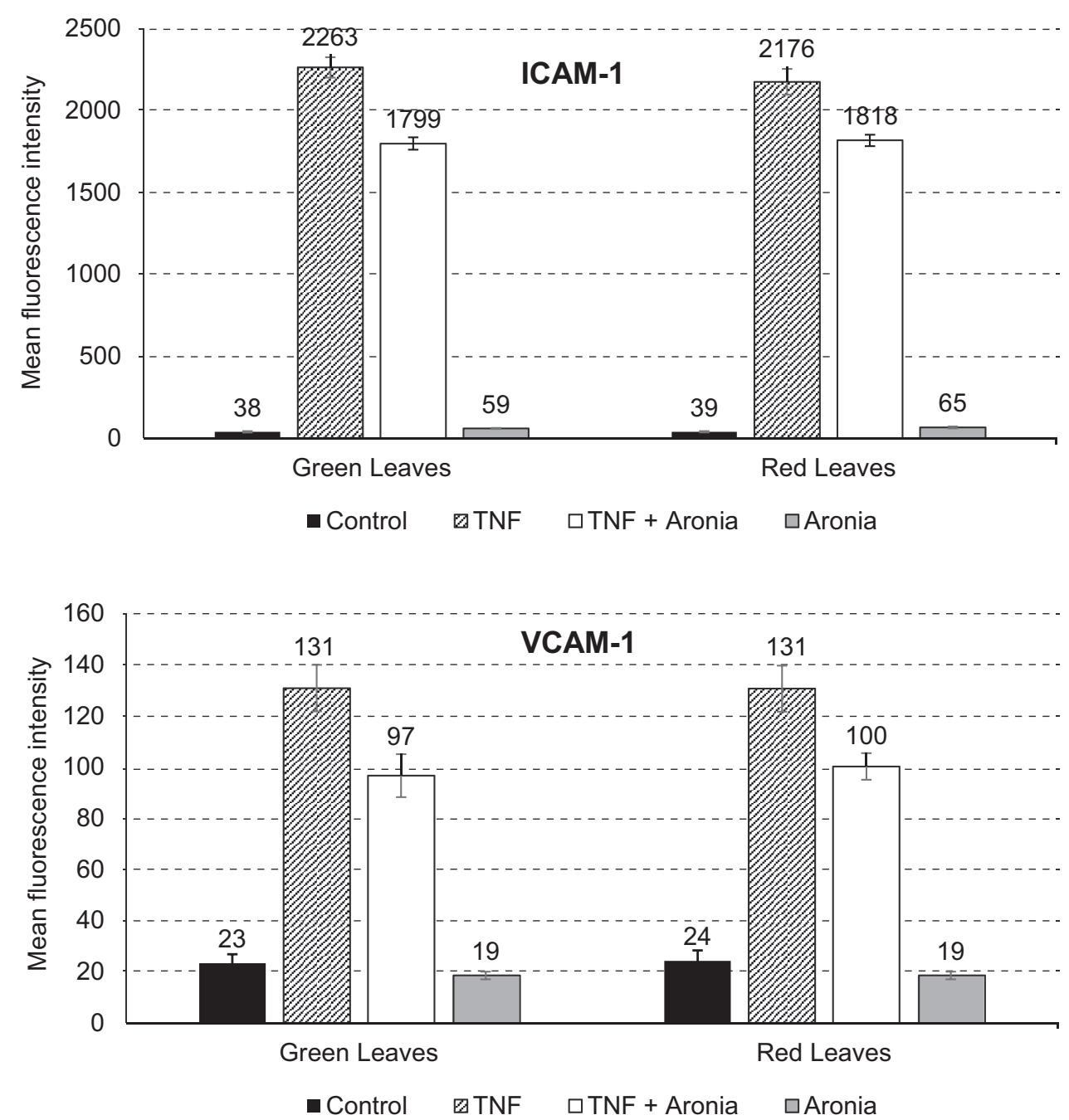

FIGURE 4. The effect of chokeberry leaf extract on ICAM-1 and VCA-1 expression after TNF $\alpha$ stimulation. Error bars indicate standard deviation $(\mathrm{n}=3)$.

difference between the young and the aged leaves in the antiinflammatory effect on endothelial cells. In this regard, red leaves can also be considered as a functional food ingredient.

\section{CONCLUSION}

Sorbitol is commonly used as a sweetening agent, an alternative to refined sugar. A. melanocarpa leaves appeared to be a rich source of sorbitol and therefore infusion (herbal tea) or the extract might be a valuable component of the diet, especially for diabetic patients. The content of sorbitol was higher at the beginning and the end of the season, but lower in the summer. The green and red leaf extracts have a rather strong anti-inflammatory effect on endothelial cells. This is probably due to the presence of chlorogenic acids and anthocyanins. Therefore, both the green leaf extract and the red leaf extract potentially can be used in functional teas, together with dried/lyophilized chokeberry fruits or fruit powders. The leaves are affordable raw material, however, it is worth remembering that collecting red leaves in the fall makes no harm to bushes, as opposed to removing them in the spring.

\section{ACKNOWLEDGEMENTS}

The authors thank Professor Włodzimierz Daniewski for his support in the experiments.

\section{RESEARCH FUNDING}

This work was supported by the Polish National Science Centre (grant number 2015/17/B/NZ7/03089).

\section{CONFLICT OF INTEREST}

The authors declare no conflict of interest.

\section{ORCID IDs}
A. Zielińska https://orcid.org/0000-0002-2244-0627
D. Bryk https://orcid.org/0000-0002-2792-4153
K. Paradowska http://orcid.org/0000-0002-9613-856X
I. Wawer http://orcid.org/0000-0002-8852-4209 


\section{REFERENCES}

1. Andrzejewska, J., Sadowska, K., Klóska, Ł., Rogowski, L. (2015). The effect of plant age and harvest time on the content of chosen components and antioxidative potential of black chokeberry fruit. Acta Scientiarum Polonorum, Hortorum Cultus, 14(4), 105-114.

2. Bagchi, D., Bagchi, M., Stohs, S., Ray, S.D., Sen, C.K., Preuss, H.G. (2002) Cellular protection with proanthocyanidins derived from grape seeds. Annals of the New York Academy of Sciences, 957(1), 260-270.

https://doi.org/10.1111/j.1749-6632.2002.tb02922.x

3. Bstfa+Tmcs Spec. (1997). Product Specification T496021. Sigma-Aldrich Co.

4. Chang, W.C., Chen, C.H., Lee, M.F., Chang, T., Yu, Y.M. (2010). Chlorogenic acid attenuates adhesion molecules upregulation in IL-1beta-treated endothelial cells. European Journal of Nutrition, 49(5), 267-275.

https://doi.org/10.1007/s00394-009-0083-1

5. Chrubasik, C., Li, G., Chrubasik, S. (2010). The clinical effectiveness of chokeberry: a systematic review. Phytotherapy Research, 24(8), 1107-1114.

https://doi.org/10.1002/ptr.3226

6. Clifford, M.N. (2000). Chlorogenic acids and other cinnamates nature, occurrence, dietary burden, absorption and metabolism. Journal of the Science of Food and Agriculture, 80(7), 1033-1043. https://doi.org/10.1002/(SICI)1097-0010(20000515)80:7<1033::AIDJSFA595 $>3.0$. CO;2-T

7. Denev, P., Kratchanova, M., Petrova, I., Klisurova, D., Georgiev, Y., Ognyanov, M., Yanakieva, I. (2018). Black chokeberry (Aronia melanocarpa (Michx.) Elliot) fruits and functional drinks differ significantly in their chemical composition and antioxidant activity. Journal of Chemistry, 2018, art.no. 9574587.

https://doi.org/10.1155/2018/9574587

8. Fotiric Aksic, M., Tosti, T., Sredojević, M., Milivojević, J., Meland, M., Natić, M. (2019). Comparison of sugar profile between leaves and fruits of blueberry and strawberry cultivars grown in organic and integrated production system. Plants, 8(7), art. no. 205. https://doi.org/10.3390/plants8070205

9. Gralec, M., Wawer, I., Zawada, K. (2019). Aronia melanocarpa berries: Phenolics composition and antioxidant properties changes during fruit development and ripening. Emirates Journal of Food and Agriculture, 31, 214-221.

https://doi.org/10.9755/ejfa.2019.v31.i3.1921

10. Gugliucci, A., Bastos, D.H. (2009). Chlorogenic acid protects paraoxonase 1 activity in high density lipoprotein from inactivation caused by physiological concentrations of hypochlorite. Fitoterapia, 80(2), 138-142.

https://doi.org/10.1016/j.fitote.2009.01.001

11. Hardin, J.W. (1973). The enigmatic chokeberries (Aronia, Rosaceae). Bulletin of the Torrey Botanical Club, 100(3), 178-184. https://doi.org/10.2307/2484630

12. Kokotkiewicz, A., Jaremicz, Z., Luczkiewicz, M. (2010). Aronia plants: a review of traditional use, biological activities, and perspectives for modern medicine.Journal of Medicinal Food, 13(2), 255-269. https://doi.org/10.1089/jmf.2009.0062

13. Kulling, S.E., Rawel, H.M. (2008). Chokeberry (Aronia melanocarpa) - A review on the characteristic components and potential health effects. Planta Medica, 74(13), 1625-1634.

https://doi.org/10.1055/s-0028-1088306
14. Lee, D. (2002). Anthocyanins in leaves: Distribution, phylogeny and development. Advances in Botanical Research, 37, 37-53. https://doi.org/10.1016/S0065-2296(02)37042-3

15. Lee, J. (2015). Sorbitol, Rubus fruit, and misconception. Food Chemistry, 166, 616-622.

https://doi.org/10.1016/j.foodchem.2014.06.073

16. Lee, J.E., Kim, G.S., Park, S., Kim, Y.H., Kim, M.B., Lee, W.S., Jeong, S.W., Lee, S.J., Jin, J.S., Shin, S.Ch. (2014). Determination of chokeberry (Aronia melanocarpa) polyphenol components using liquid chromatography-tandem mass spectrometry: Overall contribution to antioxidant activity. Food Chemistry, $146,1-5$.

https://doi.org/10.1016/j.foodchem.2013.09.029

17. Lee, S.Y., Ramirez, J., Franco, M., Lectez, B., Gonzalez, M., Barrio, R., Major, U. (2014). Ube3a, the E3 ubiquitin ligase causing Angelman syndrome and linked to autism, regulates protein homeostasis through the proteasomal shuttle Rpn10. Cellular and Molecular Life Sciences, 71(14), 2747-2758.

https://doi.org/10.1007/s00018-013-1526-7

18. Liu, D., Ni, J., Wu, R., Teng, Y. (2013). High temperature alters sorbitol metabolism in Pyrus pyrifolia leaves and fruit flesh during late stages of fruit enlargement. Journal of the American Society for Horticultural Science, 138(6), 443-451.

https://doi.org/10.21273/JASHS.138.6.443

19. Livesey, G. (2003). Health potential of polyols as sugar replacers, with emphasis on low glycaemic properties. Nutrition Research Reviews, 16(2), 163-191. https://doi.org/10.1079/NRR200371

20. Mäkinen, K.K., Söderllng, E. (1980). A quantitative study of mannitol, sorbitol, xylitol, and xylose in wild berries and commercial fruits. Journal of Food Science, 45(2), 367-371. https://doi.org/10.1111/j.1365-2621.1980.tb02616.x

21. Marinova, E., Toneva, A., Yanishlieva, N. (2009). Comparison of the antioxidative properties of caffeic and chlorogenic acids. Food Chemistry, 114(4), 1498-1502. https://doi.org/10.1016/j.foodchem.2008.11.045

22. Mikami, Y., Yamazawa, T. (2015). Chlorogenic acid, a polyphenol in coffee, protects neurons against glutamate neurotoxicity. Life Sciences, 139, 69-74.

https://doi.org/10.1016/j.lfs.2015.08.005

23. Naruszewicz, M., Daniewski, M., Łaniewska, I., Pikto-Pietkiewicz, W., Millo, B., Zapolska-Downar, D. (2003). 2P-0473 Effect of anthocyanins from chokeberry (Aronia melanocarpa) on blood pressure, inflammatory mediators and cell adhesion molecules in patients with a history of myocardial infarction (MI). Atherosclerosis Supplements, 4(2), art. no. 143.

https://doi.org/10.1016/S1567-5688(03)90615-5

24. Naruszewicz, M., Laniewska, I., Millo, B., Dłuzniewski, M. (2007). Combination therapy of statin with flavonoids rich extract from chokeberry fruits enhanced reduction in cardiovascular risk markers in patients after myocardial infraction (MI). Atherosclerosis, 194(2), art. no. e179-184.

https://doi.org/10.1016/j.atherosclerosis.2006.12.032

25. Naschitz, S., Naor, A., Genish, S., Wolf, S., Goldschmidt, E.E. (2010). Internal management of non-structural carbohydrate resources in apple leaves and branch wood under a broad range of sink and source manipulations. Tree Physiology, 30(6), 715-727.

https://doi.org/10.1093/treephys/tpq028 
26. Nii, N. (1997). Changes of starch and sorbitol in leaves before and after removal of fruits from peach trees. Annals of Botany, 79(2), 139-144.

https://doi.org/10.1006/anbo.1996.0324

27. Skoczyńska, A., Jedrychowska, I., Poręba, R., Affelska-Jercha, A., Turczyn, B., Wojakowska, A., Andrzejak, R. (2007). Influence of chokeberry juice on arterial blood pressure and lipid parameters in men with mild hypercholesterolemia. Pharmacological Reports, 59, Suppl. 1, 177-182.

28. Strigl, A.W., Leitner, E., Pfannhauser, W. (1995). Die schwarze Apfelbeere (Aronia melanocarpa) als natürliche Farbstoffquelle. Dtsch Lebensmitt Rundsch, 91, 177-180 (in German).

29. Szopa, A., Kokotkiewicz, A., Kubica, P., Banaszczak, P., Wojtanowska-Krośniak, A., Krośniak, M., Marzec-Wróblewska, U., Badura, A., Zagrodzki, P., Bucinski, A., Luczkiewicz, M., Ekiert, H. (2017). Comparative analysis of different groups of phenolic compounds in fruit and leaf extracts of Aronia sp.: $A$. melanocarpa, A. arbutifolia, and A. ×prunifolia and their antioxidant activities. European Food Research and Technology, 243(9), $1645-1657$.

https://doi.org/10.1007/s00217-017-2872-8

30. Teleszko, M., Wojdyło, A. (2015). Comparison of phenolic compounds and antioxidant potential between selected edible fruits and their leaves. Journal of Functional Foods, 14, 736-746.

https://doi.org/10.1016/j.jff.2015.02.041

31. Thi, N.D., Hwang, E.-S. (2014). Bioactive compound contents and antioxidant activity in aronia (Aronia melanocarpa) leaves collected at different growth stages. Preventive Nutrition and Food Science, 19(3), 204-212.

https://doi.org/10.3746/pnf.2014.19.3.204

32. Ulrich, E.L., Akutsu, H., Doreleijers, J.F., Harano, Y., Ioannidis, Y.E., Lin, J., Livny, M., Mading, S., Maziuk, D., Miller, Z., Nakatani, E., Schulte, C.F., Tolmie, D.E., Kent Wenger, R., Yao, H.,
Markley, J.L. (2008). BioMagResBank. Nucleic Acids Research, 36, D402-408.

https://doi.org/10.1093/nar/gkm957

33. Xia, M., Ling, W., Zhu, H., Ma, J., Wang, Q., Hou, M., Tang, Z., Guo, H., Li, Ch., Ye, Q. (2009). Anthocyanin attenuates CD40-mediated endothelial cell activation and apoptosis by inhibiting CD40-induced MAPK activation. Atherosclerosis, 202 (1), 41-47. https://doi.org/10.1016/j.atherosclerosis.2008.04.005

34. Yang, H., Kim, Y.J., Shin, Y. (2019). Influence of ripening stage and cultivar on physicochemical properties and antioxidant compositions of aronia grown in South Korea. Foods, 8(12), art. no. 598.

https://doi.org/10.3390/foods8120598

35. Zapolska-Downar, D., Bryk, D., Małecki, M., Hajdukiewicz, K., Sitkiewicz, D. (2012). Aronia melanocarpa fruit extract exhibits anti-inflammatory activity in human aortic endothelial cells. $E u$ ropean Journal of Nutrition, 51 (5), 563-572.

https://doi.org/10.1007/s00394-011-0240-1

36. Zielińska, A., Siudem, P., Paradowska, K., Gralec, M., Kaźmierski, S., Wawer, I. (2020). Aronia melanocarpa fruits as a rich dietary source of chlorogenic acids and anthocyanins: 1H-NMR, HPLC-DAD, and chemometric studies. Molecules, 25(14), art. no. 3234 .

https://doi.org/10.3390/molecules25143234

37. Zou, Y., Liao, S., Shen, W., Liu, F., Tang, C., Chen, C.-Y.O., Sun, Y. (2012). Phenolics and antioxidant activity of mulberry leaves depend on cultivar and harvest month in Southern China. International Journal of Molecular Sciences, 13(12), 16544-16553. https://doi.org/10.3390/ijms131216544

Submitted: 24 July 2020. Revised: 26 September, 8 October, and 3 November 2020. Accepted: 6 November 2020. Published on-line: 9 December 2020. 